Columbia Law School

Scholarship Archive

2018

\title{
The Systems Fallacy: A Genealogy and Critique of Public Policy and Cost-Benefit Analysis
}

Bernard Harcourt

Columbia Law School, bharcourt@law.columbia.edu

Follow this and additional works at: https://scholarship.law.columbia.edu/faculty_scholarship

Part of the Criminal Law Commons, Criminal Procedure Commons, and the Other Public Affairs, Public Policy and Public Administration Commons

\section{Recommended Citation}

Bernard Harcourt, The Systems Fallacy: A Genealogy and Critique of Public Policy and Cost-Benefit Analysis, 47 J. LEGAL STUD. 419 (2018).

Available at: https://scholarship.law.columbia.edu/faculty_scholarship/2632

This Article is brought to you for free and open access by the Faculty Publications at Scholarship Archive. It has been accepted for inclusion in Faculty Scholarship by an authorized administrator of Scholarship Archive. For more information, please contact scholarshiparchive@law.columbia.edu, rwitt@law.columbia.edu. 


\title{
The Systems Fallacy: A Genealogy and Critique of Public Policy and Cost-Benefit Analysis
}

\author{
Bernard E. Harcourt
}

\begin{abstract}
This essay identifies the systems fallacy: the mistaken belief that systems-analytic decisionmaking techniques, such as cost-benefit or public policy analysis, are neutral and objective, when in fact they normatively shape political outcomes. The systems fallacy is the mistaken belief that there could be a nonnormative or scientific way to analyze and implement public policy that would not affect political values. That pretense is mistaken because the very act of conceptualizing and defining a metaphorical system, and the accompanying choice-of-scope decisions, constitute inherently normative decisions that are value laden and political in nature. The ambition of decision theorists to render policy implementation neutral and objective by means of scientific methods was laudable, but there is no way to extract the politics from the method. The minute we are inattentive to this insight and delegate policy making to cost-benefit experts and policy professionals, we move one step closer to the systems fallacy.
\end{abstract}

\section{INTRODUCTION}

At the height of the Cold War in the late 1950s and early 1960s, decision theorists perfected a decision-making technique called systems analysis (SA) and began applying it broadly to matters of national defense strategy and social policy. The brainchild of the RAND Corporation, the method

Bernard E. HARCourt is the Isidor and Seville Sulzbacher Professor of Law and Professor of Political Science at Columbia University and a Professor at the School for Advanced Studies in the Social Sciences, Paris. I would like to especially thank William Hubbard and Edward Morrison for extraordinary editorial guidance; Jeremy Kessler, James Liebman, Stephen Macedo, Jonathan Murdoch, David Pozen, Charles Sabel, Harold Shapiro, and Linda Zerilli for exceptional and insightful comments on earlier drafts; and my faculty colleagues and participants in the Columbia Law School Faculty Workshop (December 5, 2013), the Harvard Law School Criminal Justice Roundtable (May 2, 2014), and the Princeton Law and Public Affairs colloquium (September 26, 2016) for their many reactions and suggestions. All errors are mine.

[Journal of Legal Studies, vol. 47 (June 2018)]

(C) 2018 by The University of Chicago. All rights reserved. 0047-2530/2018/4702-0024\$10.00 
of SA extended the logic of operations research (OR), which had been developed during World War II, from its earlier narrow focus on military weapons systems to broader matters of defense strategy, governmental decision-making, and public policy. Systems analysts, as their name suggests, focused on particular operational systems, such as the postal system, the emergency response system, the criminal justice system, or other social systems. They identified the scope and objectives of these systems and then collected, quantitatively assessed, and compared alternative policies for optimizing those objectives. The method was designed to be a neutral, scientific, and objective tool to more efficiently implement normative choices made through the political process. The goal was to put the science of policy decision-making at the service of democratic politics.

The method of SA had a formative impact on government decisionmaking and on social policy. In 1961, Secretary of Defense Robert S. McNamara imposed the method broadly on US Department of Defense decision-making, from weapons system procurement to national defense strategy, under the rubric of planning, programming, and budgeting systems analysis (PPBS). Within a few years, President Lyndon B. Johnson directed his budget director to implement PPBS throughout all federal agencies, extending the reach of systems-analytic methods from defense to the entire federal government. A series of subsequent executive orders under Presidents Jimmy Carter, Ronald Reagan, and Bill Clinton, as well as research advances in schools of public policy, would further extend the use of systems-analytic techniques under the rubric of cost-benefit analyses and regulatory impact statements, which resulted in the contemporary use of cost-benefit methods across governmental decision-making, especially since the establishment in 1980 of the Office of Information and Regulatory Affairs in the Office of Management and Budget within the Executive Office of the President.

The systems-analytic turn of the mid-20th century shaped the American administrative state. The logic of SA, which infused the field of public policy, is largely responsible for the dominant role that cost-benefit analysis (CBA) plays today in the US government-or, more generally, for the fact that cost-benefit reasoning has become the dominant form of rationality in our contemporary administrative state. The very notion of a system at the heart of systems-analytic methods-whether in the context of the criminal justice system, the health care system, the transportation system, and so on-has become second nature. This has had significant consequences for politics today. 
The ambition was laudable: to systematize and quantify public policy making in order to reduce costly inefficiencies and eliminate personal prejudice so that trained policy analysts could implement, rather than interfere with or distort, our political choices made through the democratic process. But when the systems-analytic methods were extended from the narrow confines of OR to the broader context of social policy, a fundamental problem arose that has plagued the use of systems-analytic reasoning since then. The analysis of a metaphorical or figurative social system, in contrast to a real or tangible system such as an engine or a military weapon, is inevitably going to involve choices regarding the scope of the metaphorical system that are invariably normative and political in nature. They are decisions that implicate political values. However, they are treated as a technical step in the SA and most often delegated to the systems analysts, public policy professionals, or cost-benefit experts rather than to the democratic political process. And therein lies the problem: systems-analytic methods are portrayed as scientific, objective, and neutral tools, when in fact they necessarily entail normative choices about political values at every key step. When those choices are made by technocrats, the methods no longer merely implement political decisions. They no longer serve democratic politics. Instead, the methods reshape our politics.

To be precise, the scope decisions in an SA include, first, the conceptualization of the metaphorical system and the decision to analyze that particular system over another; second, the identification of the boundaries of the metaphorical system; third, the determination of the objectives of the metaphorical system; fourth, the collection of the set of promising policy alternatives to evaluate in relation to that metaphorical system; and fifth, the decision of which criteria to use to judge the better functioning of the metaphorical system. Each of these scope decisions implicates core political values, and as a result conducting an SA is not a neutral, objective, or apolitical process. The decision to conceptualize and then analyze a criminal justice system, for instance, rather than another metaphorical system such as the racial equality system, will necessarily assign certain political values to central places in the SA (for example, crime prevention, security, policing, punishment) and relegate other political values to the margins (for example, racial equality, antidiscrimination, racial harmony, equal rights). Instead of directly maximizing the latter, an SA focused on the criminal justice system may indirectly undermine those political values because they are not the objective of any recognized system and thus 
will not be maximized-which can result, for instance, in the extreme disparate racial impact of mass incarceration today. Similarly, when certain alternative policies are included in an SA (for example, broken-windows policing, mandatory minimum sentences, risk prediction), but not others (for example, prison education, safe injection sites, trauma care centers), the resulting policy analysis will maximize certain political values and not others. When these scope choices are delegated to systems analysts or public policy experts, rather than determined by a political process, there is an inversion of the democratic ideal: instead of politics fixing priorities and public policy analysis neutrally implementing those political decisions, the experts and policy professionals silently impose political values on society.

This danger comprises what I call the systems fallacy: the mistaken belief that systems-analytic methods are neutral, when in fact they normatively shape politics. And even though there is little pure SA being conducted today, the systems fallacy still plagues styles of decision-making that draw on the logic of systems-analytic methods. This is true of contemporary public policy methods, which begin, as in all systems analyses, with the policy analyst collecting a set of promising alternatives, instead of leaving that value-laden choice-of-scope decision to politics. It is also true of CBA more generally-including recent, reconstructed approaches to $\mathrm{CBA}$.

Certain contemporary proponents of CBA have offered chastened versions of the method in an effort to address criticisms. They have, for instance, recharacterized the method as merely a second-best but realistic decisional tool, introduced certain limits to quantification, and urged retrospective and reiterative analyses. However, even here, if the cost-benefit analyst retains control over which policies to compare, or over the other scope decisions, there is a remnant of the systems fallacy that continues to plague these reconstructive projects. In effect, there is a systems fallacy remainder that should make one skeptical of the current use of reconstructed CBA.

By recovering the roots of contemporary CBA in OR and reexamining carefully the flaws of the systems-analytic method-in effect, by identifying a systems fallacy-it may be possible to better evaluate ongoing quantitative practices and identify their proper limits. Let me emphasize that nothing in this article should be interpreted as a criticism of being systematic. The systems fallacy is a critique of SA and its derivatives, not of being careful, rigorous, or systematic in one's thought, logic, or argumenta- 
tion. On the contrary, the critique at the heart of this article-the systems fallacy-requires rigor and systematicity to understand it properly.

This article proceeds as follows. In Section 2, it traces a genealogy of the cost-benefit approach going back to OR and the invention of SA with a case study of the emergence of the criminal justice system. In Section 3, it demonstrates the fallacy of systems thought. It then discusses, in Section 4, the implications for the field of public policy. In Section 5, it suggests directions for the proper use of quantification in decision-making, and, in a short conclusion, it points to ways forward that avoid the systems fallacy.

\section{A GENEALOGY OF SYSTEMS THOUGHT}

Military weapons SA, or what was originally called OR, was developed during World War II as a way to "provide quantitative aids to defense decision makers" with the goal of "optimizing the operational employment of existing weapons (or other military) systems" (Smith 1966, p. 6). The "distinctive approach," according to the Operational Research Society of Great Britain (1962, p. 282), was "to develop a scientific model of the system, incorporating measurements of factors such as change and risk, with which to predict and compare the outcomes of alternative decisions, strategies or controls." Famous early applications of OR include studies of the placement and use of aircraft-detection radar devices and of antisubmarine tactics involving depth-charge explosions in the early phases of World War II. A classic example of OR involves, for instance, the US Air Force's studies of bombing accuracy in the Pacific theater. These involved detailed statistical analyses of the key variables that affect the accuracy of aerial bombings, including the altitude at which the planes were flying, the visibility conditions, the wind conditions, the number and formation of planes, and the cloud strata. Weather clearly has a lot to do with accuracy, especially for visual strikes, but the studies revealed that other strategic factors play an important role as well. Formation and number of planes are determinative, for instance, as larger formations mean that later planes were affected by the smoke and dust of earlier aircraft (US Army Air Force 1945).

Eventually, OR would apply the same mathematical algorithms and

1. In the United Kingdom, where operations research (OR) largely originated, it was called operational research. For a history of OR, see Kirby (2003); Amadae (2003). 
models to larger management problems, such as the efficient determination of postal routes or warehouse stock control (Quade 1966, p. 3). From this larger perspective, OR could best be understood, again in the words of the Operational Research Society of Great Britain (1962, p. 282), as "the attack of modern science on complex problems arising in the direction and management of large systems of men, machines, materials and money in industry, business, government and defense.... The purpose is to help management determine its policy and actions scientifically." The central question was how to optimize efficiency where the measure of efficiency was clearly defined, or, as Edward S. Quade of the RAND Corporation would explain, how "to increase the efficiency of a man-machine system in a situation where it is clear what 'more efficient' means" (Quade 1966, p. 3).

During the 1950s, Quade, Alain Enthoven, Charles Hitch, and others at the RAND Corporation would extend this method of analysis from the narrow field of OR, where it had originated, to defense strategy more broadly-essentially, from deciding, for instance, the optimal altitude for a bombing mission to determining broader nuclear engagement policy. The broader application would become known as SA. Systems analysis was often confused with OR, from which it evolved, but it was distinct in several regards. Operations research tended to have more elaborate mathematical models and solve lower-level problems (Smith 1966, p. 8); in SA, by contrast, the pure mathematical computation was generally applied only to subparts of the overall problem. Moreover, SA took on larger strategic questions that implicated choices between major policy options. In this sense, SA was originally "less quantitative in method and more oriented toward the analysis of broad strategic and policy questions" (Smith 1966, p. 8).

\subsection{The Logic of Systems Analysis}

The logic of SA was straightforward and could be depicted in a simple model. A decision maker identified a particular problem to address within a particular social sphere-or what was called a system-and defined the system's objectives. With those objectives in mind, the decision maker would then set the proper criteria to evaluate promising policy alternatives. The formal analysis, then, involved five steps: in step 1, the decision maker collected a set of promising alternative policies, each of which could possibly advance the objectives of the system. Each policy was then filtered, in step 2, through a model or a set of models to assess its indi- 
vidual attributes in terms, for example, of maintenance costs, manpower requirements, communication capabilities, and so on. This produced each policy's level of effectiveness and cost in step 3, which could then be compared using a metric or the criteria in step 4, which would then turn out, as the output in step 5 , the relative rank of each policy compared with the others. The output was the correct ordinal ranking of the alternative policies. To perfect the method, the operation could be reiterated to test for sensitivity, question assumptions, reexamine objectives, explore alternatives, and tweak the model. Quade (1966, figure 1) depicts well the five key steps of the analytic decision-making method (see Figure 1).

Trained in OR during World War II, Robert McNamara would impose this systems-analytic method, under the rubric of PPBS, on all military procurement and defense strategies when he took office as secretary of defense under President John F. Kennedy in 1961. This represented a significant expansion of the method-from narrow OR on military weapons systems to broader applications of SA to defense strategy-and it generated a lot of resistance within the military establishment, targeted primarily at the controversial figure of McNamara himself. But, in the opinion of Quade (1966, p. 2), by 1966 "there ha[d] been substantial progress, and the years since 1961 have seen a marked increase in the extent to which analyses of policy and strategy have influenced decisionmakers on the broadest issues of national defense."

Johnson would expand the reach of the systems-analytic method even further, announcing in a statement to members of his cabinet and heads of federal executive agencies on August 25, 1965, that he had instructed his budget director, Charles Schultze, to implement the PPBS method throughout all federal agencies. Johnson emphasized that PPBS would "identify national goals with precision and on a continuing basis," help "search for alternative means of reaching those goals most effectively at the least cost," and accurately "measure the performance of programs to insure a dollar's worth of service for each dollar spent" (US General Accounting Office 1969, p. 4).

This additional expansion of SA to all governmental decision-making was even more significant—or, in the words of Quade (1966, p. 2), "even more radical" - than the earlier expansion of OR. It carried the possibility of major innovation. As Quade (1966, p. 7) explains, alternative policies are not always "obvious substitutes for one another," nor do they always "perform the same specific function." It might turn out, for instance, that as a matter of social policy "education, antipoverty measures, police pro- 

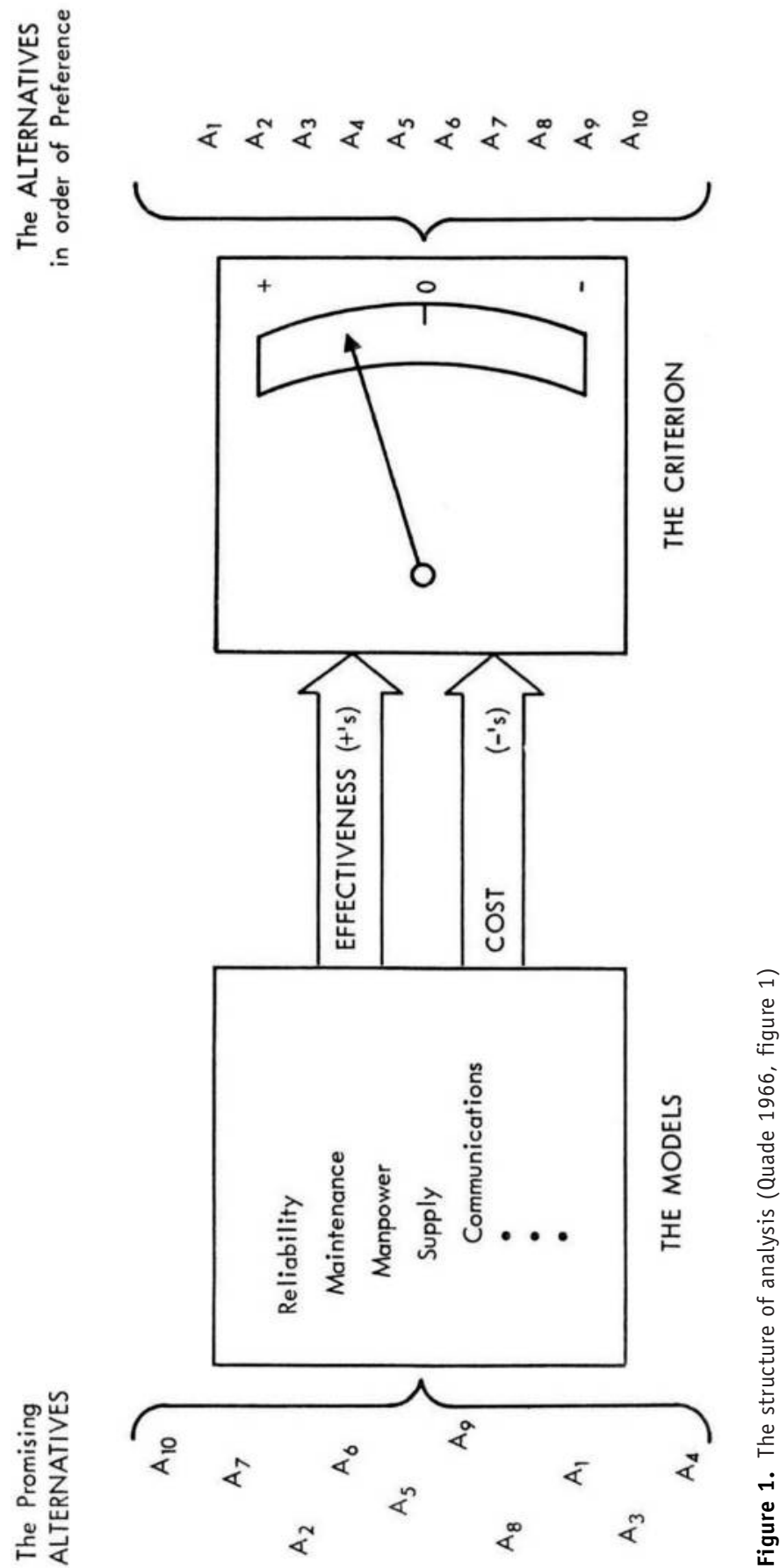

This content downloaded from 128.059.191.084 on April 01, 2020 06:45:19 AM All use subject to University of Chicago Press Terms and Conditions (http://www.journals.uchicago.edu/t-and-c). 
tection, and slum clearance may all be alternatives in combating juvenile delinquency" (Quade 1966, p. 7). Any of those alternative policies might be called for by rigorous analysis. In other words, policing and education are fungible substitutes, and either one may be called for on the basis of the cost-effective pursuit of the objectives of the juvenile justice systembased on an SA. Moreover, systems-analytic methods may give one the tools to decide whether "additional money might be better spent on space exploration or economic opportunity programs" or whether to "reduce unemployment to less than $2 \%$ in two years or add a certain number of miles to the interstate highway system" (Quade 1966, pp. 18, 4-5).

In effect, according to its proponents, SA would allow trained analysts to put aside their own personal preferences, subjective values, and partisan politics and instead neutrally and efficiently implement political choices. As RAND colleague and later secretary of defense James R. Schlesinger explained, "[SA] eliminates the purely subjective approach on the part of devotees of a program and forces them to change their lines of argument. They must talk about reality rather than morality" (Schlesinger 1963, p. 314). With this new method, Schlesinger suggested, a neutral answer would emerge from an analysis of cost and effectiveness. All that was needed was a narrow and precise objective.

While Johnson was the first to impose cost-benefit accounting on federal agencies, only a decade later Carter's Executive Order No. 12,044 (43 Fed. Reg. 12,661 [March 24, 1978]) tasked all executive agencies with the duty to conduct economic impact studies of all major government regulations. Reagan's Executive Order No. 12,291 (46 Fed. Reg. 13,193 [February 17, 1981]) assigned the responsibility to the Office of Management and Budget, which now oversees and coordinates economic impact analyses. Clinton continued in this tradition with Executive Order No. 12,866 (58 Fed. Reg. 51,735 [October 4, 1993]), which required economic impact analyses of all significant regulations. And in 2011, President Barack Obama "renewed and deepened the commitment to quantitative, evidence-based analysis, and added a number of additional requirements to improve regulatory review, directing agencies 'to use the best available techniques to quantify anticipated present and future benefits and costs as accurately as possible' in order to achieve regulatory ends" (Clarke et al. 2014, pp. 50-53). The influence of SA continues to the present as the method has evolved in public policy and CBA. The commitment to quantitative, evidence-based, and modeled methods re- 
mains strong, even as some aspects of CBA have been updated and now include more retrospective analysis.

\subsection{A Case Study from the Criminal Justice System}

During the Progressive Era, reformers had already gravitated toward an early notion of systems, especially with regard to the treatment of juvenile offenders. ${ }^{2}$ One of the first uses of the term "criminal justice system" occurred in Youth in the Toils, a study conducted on behalf of the Delinquency Committee of the New York City Boys Bureau (Harrison and Grant 1938). In the following years, the term would be used in several other publications, each time to refer again to the problem of juvenile delinquency (Ellingston 1948; Phillips 1942; MacCormick 1942).

Those early references to a criminal justice system would gain traction with the emergence of SA at midcentury such that, by the 1960s, the field of criminal justice began to be understood as a relatively enclosed system in which particular sets of actors (police officers, prosecutors, judges, probation officers, correctional guards, wardens, parole board members, and so on) operate a defined set of institutions (police forces, courts, jails, prisons, parole supervision, and so on) to promote a distinct set of systems objectives (crime control, population management, servicing needs, and so on) and produce a functioning system (see, for example, the graphic representation of the criminal justice system in President's Commission on Law Enforcement and the Administration of Justice [1967, p. 8]).

Systems analysis played a key role in crystalizing the notion of a "criminal justice system," and a genealogic link can be traced at both the individual and institutional levels. Alfred Blumstein, for instance, a towering figure in American criminology, began as an operations researcher, was president of the Operations Research Society of America, and considers himself an "OR missionary"-tellingly, his appointment at Carnegie Mellon is University Professor of Urban Systems and Operations Research, Emeritus (Blumstein 2007). Institutions also sprang up early to analyze the criminal justice system, as illustrated, for example, by the creation in 1966 under Mayor John Lindsay of the New York City-RAND Institute, a joint project of the city and the RAND Corporation (Light 2003, pp. 68-72).

2. For a detailed history of the concept, discussion of the criminal justice system's relation to judicial decision-making, and the ramifications for law and public policy, see Harcourt $(2013,2014)$. 
Lindsay took office in 1966 promising to bring the PPBS method to New York City “to improve budgeting and operations" (Light 2003, p. 67). At the time, violent crime in the city was on the rise, and the problem of crime was particularly acute in public housing projects (see, for example, Rosenthal 1972; Seigel 1972). So Lindsay invited the RAND Corporation to develop new strategies to reduce crime.

The New York City-RAND Institute immediately began to tackle the crime problem with a number of highly technical OR reports with titles such as "A Hypercube Queueing Model for Facility Location and Redistricting in Urban Emergency Services" (Larson 1973), "Response of Emergency Units: The Effects of Barriers, Discrete Streets, and One-Way Streets" (Larson 1971), "Analysis of the Night and Weekend Arraignment Parts in the Bronx and Queens Criminal Courts" (Jennings 1973), and "Determining the Travel Characteristics of Emergency Service Vehicles" (Hausner 1975). These studies resembled the early applications of OR outside the military to matters such as determining "how Post Office pick-up trucks should be routed to collect mail from deposit boxes, or whether computers should be rented or purchased ..., or what type of all-weather landing system should be installed in new commercial aircraft" (Quade 1966, p. 3).

Gradually, and interspersed in these OR reports, the New York CityRAND Institute began publishing a number of SA-style studies. An illustrative study was Michael I. Liechenstein's report issued in June 1971, which addressed the objective of reducing crime in public housing.

Liechenstein (1971, p. 4) took a "broad operational view of a security system" and identified promising policy alternatives, including tenant training and education, tenant patrols, tenant qualifications to live in the projects, extended recreational opportunities for teenagers, rent rebates, elaborate building-entry restrictions, locked lobbies, intrusion detectors, weapon detectors, surveillance, and increased police or guard manning. In order to compare security systems, Liechenstein (1971, p. 5) developed "effectiveness criteria" and then attached those to "compatibility and cost criteria to derive estimates of an overall figure of merit (e.g., the ratio of effectiveness-to-cost with a constraint on either minimum effectiveness or maximum cost)." Liechenstein $(1971$, p. 6) also identified cost-benefit criteria: "[r]esearch and development cost (equipment, maintenance, administration before production)[, c]apital cost (equipment, maintenance, and administrative costs during production)[, o]perating cost (equipment, maintenance, administration costs during use)[, s]crap value (residual 


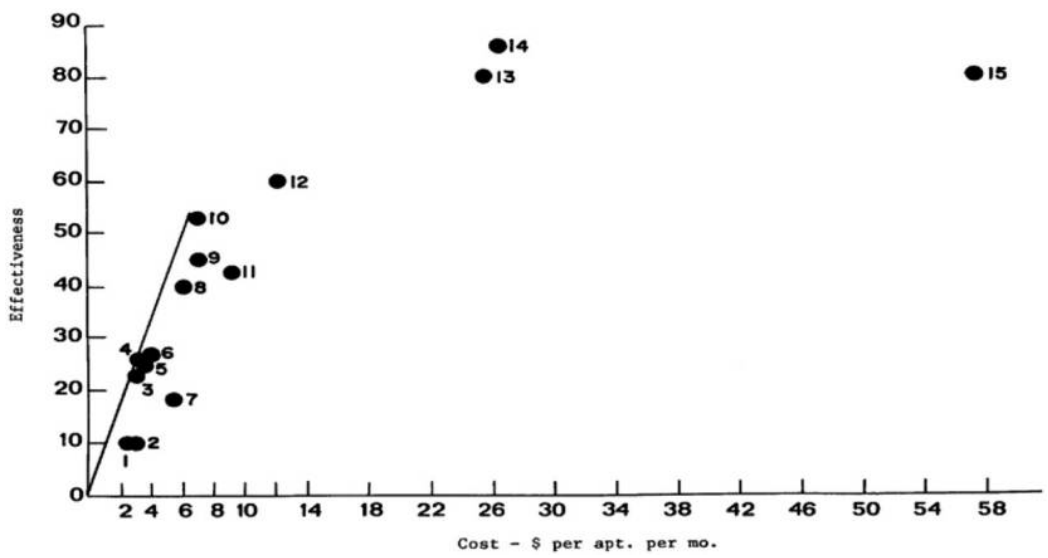

Figure 2. Average effectiveness-to-cost ratios of security options (Liechenstein 1971, p. 23).

value at end of use)[, e]xpected total benefit." Liechenstein then ran an SA and generated a graph of the cost-effectiveness of 15 alternatives (see Figure 2).

Liechenstein had originally identified alternatives that reflected varied political values-from education for low-income tenants on issues of criminal offending and self-defense, to providing recreational facilities for poor urban teenagers, to offering subsidies and other financial incentives, to raising admissibility and tenure standards for housing assistance, to increased police presence. They included everything from education to recreation, to target hardening, to policing. But on the basis of the SA, Liechenstein found that the most effective measure was an increase in the police force and more guards. ${ }^{3}$

New York City implemented these policies, focusing precisely on increased policing and personnel. Simeon Golar, chairman of the New York City Housing Authority, instituted a " 100 -man mobile task force' consisting of 40 housing policemen and the hiring of 60 new policemen" (New York Times 1971), and there followed a \$500,000 initiative to hire

3. The study ultimately suggested that the most effective security measures-extensive surveillance, increased policing, and posting of armed guards at each building-were too expensive (Liechenstein 1971, p. 24) and, as a result, did not specifically endorse the security measures. Instead, the study intimates that there is a need for more systems-analytic research like that of the New York City-RAND Institute (Liechenstein 1971, p. 24). Nevertheless, the city implemented the policies that topped Liechenstein's study. 
armed and unarmed guards for the city's housing projects and a $\$ 1$ million allocation for security and surveillance equipment (Ranzal 1973).

The New York City-RAND Institute ultimately folded in 1975 amid significant controversy, ironically, over Lindsay's profligate spending on consultants (Light 2003, p. 74). But the notion of the criminal justice system would stick, and the systems-analytic approach would lead to a number of institutions and think tanks, across the political spectrum, that would take as their object the criminal justice system—such as the Vera Institute of Justice, the Urban Institute, the Police Foundation, the Police Executive Research Forum, and the Institute for Law and Justice, to name a few. Today, the idea that there exists such a thing as the criminal justice system has become so dominant that practically everyone thinks about crime and punishment through a systems-analytic lens and uses this language and logic in a secondhand way.

\section{THE PROBLEM WITH SYSTEMS-ANALYTIC REASONING}

Decision theorists developed systems-analytic methods with the laudable goal of preventing subjective preferences from trumping democratic choices. Over time, the implementation of these methods was delegated to professional analysts and public policy experts on the ground that the methods were neutral and objective, in other words, scientific. But the core decisions at the heart of systems-analytic methods-namely, the recurring choices of scope at every key step of the analyses-were and remain entirely normative and, as a result, end up shaping political values. The choice to conceptualize a metaphorical system, to define it and its boundaries, to identify its objectives and criteria, to collect promising policy alternatives-all these key scope decisions affect the political outcomes. And the moment those choices are delegated to the policy analyst rather than to the democratic process, the systems-analytic method has turned on its head the proper relationship between politics and public policy: instead of public policy implementing democratic political decisions, public policy drives political outcomes and values.

The seed of the problem is illustrated well by the observation in Quade $(1966$, p. 7) that "education, antipoverty measures, police protection, and slum clearance may all be alternatives in combating juvenile delinquency." Notice how the systems analyst here, Quade himself, silently assumes one particular metaphorical system rather than another (namely, 
a juvenile delinquency system rather than a juvenile welfare system) and chooses a set of policies without acknowledging that they each embrace very different political values, such as an educated citizenry and a robust public sphere (education), political and economic equality (antipoverty measures), security (police protection), and urban planning (slum clearance). In the process of choosing promising alternatives and excluding others, Quade effectively defines the scope of the metaphorical system and its objectives (namely, combating juvenile delinquency, instead of improving the welfare or life opportunities of youths). This is done under the guise of neutral, scientific policy analysis. Yet the simple act of choosing the set of promising alternatives to compare, and excluding others, performs normative work-normative work that is hidden behind a veil of objectivity. The chosen set of alternative policies cuts across multiple values, and the policy output, if implemented, will necessarily affect and reshape the balance of political values in our democracy. The choices of the systems analyst - namely, which metaphorical system to study, which policy alternatives to include, how to define the boundaries and objectives of the system, which criteria to test-end up shaping societal values.

\subsection{The Systems Fallacy}

The systems fallacy is the mistaken belief that systems-analytic methods are neutral and objective. It occurs when one mistakenly assumes that there is a nonnormative way to identify a metaphorical system, to select its proper boundaries, or to collect possible policies to compare-in effect, to make any of the key choice-of-scope decisions. In any such analysis, the expert will include some promising policy alternatives that may change the political landscape (for instance, slum clearance, if that might entail displacing communities or disrupting family bonds) but invariably exclude, crowd out, or discount other alternatives, perhaps because they are more creative or marginal to the system studied. It is precisely when one forgets that the methods involve normative political choices and assigns them to policy professionals that the systems fallacy problem recurs.

There are a number of other problems with systems logics that have been well articulated by other critics, especially in the contemporary debate over CBA (Sinden 2004, p. 191; Sinden, Kysar, and Driesen 2009; Kysar 2007; Farber 2009, p. 1355; Ackerman and Heinzerling 2004). As others have noted, a systems-analytic approach privileges certain kinds of quantifiable interests over less quantifiable values. By selecting more quantifiable objectives and variables (for instance, juvenile delinquency 
rates), which the method itself demands, rather than larger social values (for instance, youth welfare), and by focusing exclusively on measurable outcomes, the systems-analytic approach privileges the more quantifiable, measurable, and instrumental factors in the analysis. Educational alternatives, for instance, often will get short shrift because of the difficulty of assessing their long-term benefits. Poverty reduction and other soft variables will be more difficult to measure in terms of impact and outcomes. The hard edge of the systems-analytic approach often favors hard systems.

Another common criticism is that the analysts often do not have the skills, background, knowledge, or time to implement the type of quantitative analysis necessary to properly identify a best alternative, so they tend to guesstimate and, in the process, simply confirm their personal biases. This is the critique expressed by scholars such as Charles Lindblom, who argues that policy makers just "muddle through," or Herbert Simon, who coined the term "satisfice" (Simon 1997; Lindblom 1959, 1979; Rubin 2013, pp. 38-39). These critiques raise the problem of bounded rationality, and they too are undoubtedly correct.

But an equally pressing problem of systems-analytic methods is the systems fallacy, namely, the fact that choice of scope is never neutral, objective, or scientific but inherently normative and has deep political implications that are masked precisely by the purported scientific nature of the method. This can be demonstrated using a simple hypothetical.

\subsection{A Simple Demonstration}

Let me begin with a simple model that assumes, hypothetically, that Americans in the aggregate would like to distribute their resources in line with their political values in the following manner: 50 percent to education, 35 percent to health care, and 15 percent to policing. For those who prefer to rely on revealed preferences, I could hypothesize that these are actual budgeted expenditures. I emphasize, at the outset, that this particular distribution is itself, of course, the product of socialization; there is no prepolitical starting point or state of nature. But for purposes of this simple demonstration, I will start at one historical moment.

At time 1, then, this distribution of preferences (call them revealed preferences if you prefer, or budgets, utilities, or priorities) corresponds to a certain weighting of political values that puts a priority first on an educated and healthy citizenry (call this liberty) and second on security and orderliness (call this order). Again, to keep it simple and take only 
two values, imagine the relationship as follows: the first value (the liberty associated with an educated and healthy citizenry, 85 percent) is, under this hypothetical, more than four times as important as the second value (the order associated with orderliness and security, 15 percent).

Now suppose that Americans choose to address a social problem such as crime through a systems-analytic approach. As decision makers, we begin by identifying the objectives-here, reducing crime most efficiently-and collecting a set of promising alternatives to maximize that objective. Suppose, for simplicity, that we collect three promising alternatives: investing more in educational programs, increasing the number of drug rehabilitation programs, or increasing the police force. We then conduct a detailed CBA and find, hypothetically, that a similar monetary investment will have the greatest return if the third policy, increasing the police force, is adopted. On the basis of the analysis, we increase the number of police officers and the budget for police. Now the distribution of resources or our budget has become, hypothetically, 33 percent investments in police, 33 percent health initiatives, and 33 percent education.

This reallocation of resources and new distribution, at time 2 , has affected our political values. As we make those new investments to most efficiently reduce crime, we are now investing twice as much in policing than we were before, and this has an effect on the balance of political values reflected in our society, with order and security now being proportionally more important than before. Focusing on a narrow objective (crime reduction) and selecting a set of alternative policies (the three that were chosen) has reshaped our politics. We could, of course, have excluded the third alternative or added others. Those choices will inevitably affect our political preferences and vision for society-they will alter the world in which we live. In this sense, the systems-analytic method begins with a limited mission-defining an objective and identifying a set of promising alternatives-but inevitably reaches much further and transforms our societal balance of political values. It imposes new distributions of values under the guise of science. It displaces political deliberation with policy analysis.

It has done this on the basis of maximizing a social welfare function and concluding that the gains from policing offset the losses in education and health. We are assuming, naturally, that at time 1, the marginal benefit of further investment in any one area is equal to the marginal cost for each sector under a welfare function and that the reallocation at time 2 maximizes the social welfare function. But it is important to emphasize 
that, although our welfare may have been maximized, the new allocation of resources reflects a different weighting of political values: it produces a different political landscape.

\subsection{The Matter of Partial Maximization}

At this point, a proponent of SA might respond that it is easy to ensure that political preferences are respected and that the analysis takes full account of democratic choices. Suppose that, as a result of the increased investment in policing, welfare may be lower than what we might have expected from the drop in crime, because of a shared distaste for living in a more policed state; in other words, the benefits of reduced crime may be offset to some degree by the increase in policing. That, a proponent might argue, can and must be factored into the analysis-and already has been if the social welfare calculus was properly done. The analysis would have included in the model the distaste (disutility) associated with the increased policing. Preferences along these lines can be measured and quantified and should be made part of the overall calculus. The problem, in other words, has been addressed by factoring in people's tastes and preferences.

Now, of course, if we etch those preferences too deeply into the welfare analysis, then we will simply be back at square one: we will weight our political preferences so strongly that our values will determine policy outcomes. If the policy analyst is going to factor in our taste for police surveillance robustly-as well as all our other tastes for civil liberties, for equality, for an educated citizenry, and so on-then the model is essentially rigged to produce the outcomes that mirror our values and our original distributions at time 1 . The analyst will simply reproduce the landscape at time 1 , and there would be no need for SA.

The question thus becomes how deeply to etch preferences into the model. There is no reason to believe that preferences are unchangeable and that there could not be any trade-offs. A systems-analytic approach might find real efficiencies that will result in increased welfare and greater utility overall even if they shift our balance of political values.

This is the welfare economist's response- a type of response consistent, for example, with Louis Kaplow and Steven Shavell's thesis in Fairness versus Welfare (Kaplow and Shavell 2002). In fact, Kaplow and Shavell make precisely this argument. As they emphasize, "The conception of individuals' well-being that we consider, in the tradition of welfare economics, is a comprehensive one. It encompasses not only the di- 
rect benefits that individuals obtain from the consumption of goods and services, but also individuals' degrees of aesthetic fulfillment, their feelings for others, and anything else that they value" (Kaplow and Shavell 2003, pp. 332-33). As if anticipating the argument here, Kaplow and Shavell (2003, pp. 333) add, "An implication of our broad definition is that even tastes for fairness are included: Just as an individual might derive pleasure from art, nature, or fine wine, so might an individual feel better with the knowledge, for example, that vicious criminals receive their just deserts." In other words, welfare economics can incorporate preferences regarding political values and still optimize by shifting policies around to find efficiencies that can be reinvested along other desired political dimensions.

This is undoubtedly right, at least at a theoretical level. But the problem is, even from a welfare economist's perspective, that a systemsanalytic approach then maximizes the wrong thing: it is trying to resolve one specific, identified social problem instead of trying to maximize general social welfare. In the process, there is absolutely no way to know whether the resolution of that particular problem has increased or decreased overall welfare or whether there are other policy alternatives related to other social problems that would do better at promoting overall social welfare.

In other words, from an internal perspective-internal to welfare economics-SA is dangerous: it is trying to optimize the wrong objective. From a social welfare point of view, it would be crucial not to engage in partial welfare analyses by focusing on one metaphorical system. To do so would simply distort overall welfare. ${ }^{4}$

An illustration may be helpful: suppose that the policy of mass incarceration was cost-effective insofar as it accounted for one-third of the overall drop in crime in the United States during the 1990s (Levitt 2004, pp. 178-79; but see Harcourt 2006, pp. 1762-63). Suppose, in fact, that it was determined to be the most effective policy of all the alternatives

4. This point differs from the other critiques that have been leveled at Kaplow and Shavell's argument. See Chang (2000a, 2000b); Craswell (2003), which defends a mixed theory that privileges fairness in most cases; Dorff (2002); Fallon (2003); Ferzan (2004); Kornhauser (2003), which challenges the copious definition of well-being that includes fairness; Singer (2002), which argues that the authors define fairness improperly and create a straw-man argument; Waldron (2003), which challenges the line between distribution and the authors' definition of fairness and calls for greater attention to the issue of distribution; and Stewart (2004). 
studied and compared to address the crime problem. Suppose, however, that the investment itself-more than $\$ 50$ billion per year, over the course of 40 years-if it had been invested instead in cancer research, would have resulted in finding a cure for cancer. The result of the partial SA focusing only on the limited problem of crime, and not on overall welfare, is that we would have overinvested in prisons and underinvested in cancer research. In effect, it would have produced mass incarceration during a period marked by low levels of crime (recall that, on these assumptions, crime would have fallen 66 percent in the 1990s because of other factors; see Levitt [2004], p. 184), with no cure for cancer. That is clearly a net loss to society. But it is the direct consequence of having conducted a partial CBA rather than an overall welfare calculus. It is the result of focusing on one metaphorical system without recognizing the opportunity costs of investing instead in a more broadly conceived social space.

Another way to think about this is that SA does not address the key question of how a particular metaphorical social system becomes the focus of the analysis. The problems of crime and the criminal justice system, for instance, were turned into major national issues at a particular moment in history, in the early 1960s, during Barry Goldwater's presidential campaign and would become key campaign issues for President Richard Nixon. In part as a backlash to the civil rights movement and for other reasons-including the rise of the antiwar and other social movements and increasing racial tension-crime and the criminal justice system would become the focus of analysis in the 1960s and trump other social problems, such as poverty, inadequate public housing, and lack of proper health care (Beckett 1997). But there was nothing natural about that. Illiteracy, malnourishment, poverty, racism, inequality, or homelessness could instead have become the pressing social problem and the focus of SA.

In other words, the choice of which metaphorical social system to analyze and remedy, as well as all the choice-of-scope decisions, have political consequences. The only way to do SA without causing these systemic distortions would be to do general welfare analysis at the highest and broadest level. But that, of course, entails other costs that may be prohibitive. Section 5 addresses other possible solutions. For the time being, it is important to recognize here that the systems-analytic methods themselves inevitably shape our political landscape. The methods are not scientific, objective, or neutral, but political. 


\section{THE IMPLICATIONS FOR PUBLIC POLICY}

Systems-analytic reasoning significantly influenced public policy analysis and, in some circles today, still dominates the field of public policy. What was once technical SA in the 1960s has become, for many, the canonical approach to public policy analysis. Here too, then, one needs to pay attention to the systems fallacy.

\subsection{Classical Public Policy Analysis}

Public policy analysis was born of the systems-analytic method, and the canonical expressions of public policy methodology by the leading figures in the field, such as Eugene Bardach, Thomas Birkland, John Friedman, and Richard Zeckhauser, mirror Edward Quade's original model. Edith Stokey and Richard Zeckhauser set forth the proper sequence of analysis in their canonic text on public policy analysis, A Primer for Policy Analysis, as follows:

Establishing the Context. What is the underlying problem that must be dealt with? What specific objectives are to be pursued in confronting this problem?

Laying out the Alternatives. What are the alternative courses of action? What are the possibilities for gathering further information?

Predicting the Consequences. What are the consequences of each of the alternative actions? What techniques are relevant for predicting these consequences? If outcomes are uncertain, what is the estimated likelihood of each?

Valuing the Outcomes. By what criteria should we measure success in pursuing each objective? Recognizing that inevitably some alternatives will be superior with respect to certain objectives and inferior with respect to others, how should different combinations of valued objectives be compared with one another?

Making a Choice. Drawing all aspects of the analysis together, what is the preferred course of action? (Stockey and Zeckhauser 1978, pp. 5-6)

The five-step method is practically identical to SA. Underlying the public policy mission is a similar belief that there exists, in practically all domains, the opportunity to deploy the method to determine the most efficient course of action. But it is precisely here that the systems fallacy surfaces again and raises difficulty, just like a crystalline structure (Balkin 1986): the same problems arise of normative choice-of-scope decisions masquerading as policy science but ultimately shaping political values. 


\subsection{Reconstructed Cost-Benefit Analysis}

As Geertz (1973) remarks, most ideas begin as large systems and are then incrementally trimmed to size. A number of scholars have proposed today more chastened versions of CBA to address the many criticisms and concerns leveled against classical forms of CBA. There have been several proposals to reconstruct $\mathrm{CBA}$ along more pragmatic and flexible lines: by saving the valuable part of CBA as a tool to assess programs and policies while eliminating the unnecessary accoutrements and by crafting a humbler, second-best method to guide decision-making.

Cass Sunstein has taken, for many years now, a more limited or what might be called pragmatic approach to CBA, both in theory and in practice (Sunstein 2001-2, 2002, 2013). Sunstein's more pragmatic approach is reflected, by no coincidence, in Obama's Executive Order No. 13,563, which suggests, for example, that agencies "may consider (and discuss qualitatively) values that are difficult or impossible to quantify, including equity, human dignity, fairness, and distributive impacts." Both in his official functions and in his scholarly writings, Sunstein has helped soften the edges of CBA, emphasizing a greater recognition of the limits of quantification, of the difficulties of monetary measures, and of translating everything into dollar equivalents—all the while, though, being a strong proponent of CBA.

In a similar vein, Matthew Adler and Eric Posner, in their book New Foundations of Cost-Benefit Analysis and other work, have proposed a more limited, pragmatic approach (Adler and Posner 2006, 2009). They suggest that we should think of the method not as an ideal, first-order technique that provides unassailable answers but rather as a second-best device for making decisions, one that is more suited to our current epistemological and political condition. The CBA method, they argue, should be thought of as just that: a decision-making method. And as such, they argue, it is nothing more than a "rough and ready proxy" for the kind of welfare analysis that we would ideally want to engage in if we lived in a perfect world but that is sufficient in the real world to achieve the tasks at hand (Adler and Posner 2006, p. 25). It should be viewed as a kind of "weak welfarism" in which "overall well-being is one of a possible plurality of fundamental moral considerations" (Adler and Posner 2008, p. S255). In presenting the method in this way, Adler and Posner recognize that there are difficulties with quantification and CBA but argue that any problems with the method do not cause sufficiently significant 
distortions to warrant concern. A CBA, they argue, should be seen as an "imperfect decision procedure" that "roughly" provides a best fit (Adler and Posner 2009, p. 72).

These more pragmatic approaches have introduced certain deontological limits to quantification. So, for instance, in a coauthored report following the Edward Snowden revelations, Sunstein argues that, regardless of the cost-effectiveness of certain policies, "some safeguards are not subject to balancing at all," and those include restricting free speech or religion or suppressing legitimate dissent (Clarke et al. 2014, p. 16). Here, the reconstructed cost-benefit method expressly takes some factors off the table. It draws deontological limits on the scope of the method itselflimits that would be entirely antithetical to a full-blown, robust welfare calculus. In addition, central to many of these reconstructive projects is the idea of reiterative or retrospective evaluations as a way to properly update information over time (Clarke et al. 2014, p. 16).

These three components-a more limited decision-making technique, with certain deontological limits, that is updated through retrospective analysis-constitute a new, more chastened version of CBA. Some scholars, such as Amy Sinden, refer to this reconstructed version as "costbenefit lite" (Sinden 2004, p. 191).

\subsection{The Systems Fallacy Remainder}

Critics of the new reconstructed cost-benefit approach argue that the earlier criticisms still apply and should thus make us skeptical. As some of the leading critics-Amy Sinden, Douglas Kysar, and David Driesen-remark, the reconstructed approach "suffer[s] from all the same shortcomings they associate with direct implementation: inaccuracy, vulnerability to manipulation, and inordinate expense" (Sinden, Kysar, and Driesen 2009, p. 58).

Although these criticisms are valid, it is important to emphasize two other problems. First, the notion of a second-best decision-making tool does not resolve the problem of partial maximization: if one believes that the kind of quantitative analysis that is called for by the reconstructive project is doable, if one believes that those types of measurements and metrics are sufficiently reliable to decide, effectively, life-or-death questions, as the proponents of reconstructed CBA suggest, then one would have to engage in the higher-level welfare analysis, since, as discussed earlier, anything short of that would distort outcomes.

But second, and more important, nothing in the reconstructed project 
addresses the fact that the recurring choice-of-scope decisions are normative questions of political values. Nothing changes the inherently political character of the central decisions at the heart of CBA. So, once again, it would be misleading to suggest that the reconstructed CBA offers a neutral or objective, even if limited, determination of policies. It too is a political enterprise involving central questions of political values. Failing to put that front and center will mean that the method of analysis ultimately distorts, rather than serves, politics.

\section{THE PROPER PLACE OF QUANTIFICATION}

It is important to emphasize that the problem of the systems fallacy does not mean that we should be unsystematic or in any way opposed to rigor in our evaluation of social policies. To the contrary, understanding the systems fallacy requires systematic rigor. It also helps to delineate more precisely the proper place of quantification and modeling in politics. The systems fallacy reveals the normative choice-of-scope decisions inherent to systems-analytic methods: the normative dimensions of identifying a social problem; of imagining a metaphorical system; of setting the boundaries, objectives, and criteria of such a system; and of collecting possible alternatives to compare. This suggests two possible avenues.

One direction would be to forgo analyses that construct metaphorical systems and bounded sets of promising alternatives and instead implement public policies on the basis of political values determined through the democratic process. This alternative would obviate the need for comparative CBA, though it would not necessarily exclude metrics or uses of benchmarks to assess the individual policies or regulations. Evaluating the effectiveness of a program would, of course, remain important. If a program selected on the basis of political values is not contributing to the political objective or is counterproductive, that is important information to have. For example, if broken-windows policing or stop-and-frisk policies are not reducing crime, it is important to know in order to decide whether to engage in those enforcement practices (Fagan and Davies 2003; Harcourt and Ludwig 2006, 2007). It is important to remain cognizant of efficacy questions without letting those concerns trump the political balancing of values. But if metrics are going to be used here, their inclusion should be limited to an individualized analysis along a single value dimension: the metrics would focus on a single program, not on a 
system or a set of promising alternatives. There are, for example, uses of benchmarking that have been advocated by scholars such as Christopher Ansell that stay within a single value dimension (Ansell 2011; Liebman, Cruikshank, and Ma 2017, p. 417; Sabel and Simon 2011). Such quantitative approaches can stay clear of the systems fallacy by focusing on a single program or regulation and not on a figurative system or set of promising alternatives, by concentrating on a single value domain, and by always being attentive to hidden choice-of-scope issues that might arise.

A second approach is to politicize the public policy and CBA: to explicitly recognize that these methods are not neutral or objective, but deeply political, and must be determined through democratic political processes. This would require that every scope decision at every step of the analysis be subject to a political, not a technocratic, decision-making process. The key steps would include, at a minimum, the conceptualization and definition of the metaphorical system; the identification of its boundaries, objectives, and criteria of operation; the collection of alternative policies and the metrics used to assess and compare; and all of the retrospective analysis and reevaluation. This would not solve the problem of partial maximization, but it would address a key element of the systems fallacy.

The fact is, decision theorists turned to systems-analytic methods in large part because total welfare analysis was viewed as too unwieldy for policy making, but the turn to SA hid the political dimensions that were more obvious in welfare analysis. If Americans decide to retain a welfarist approach to improve the decision-making process, then we would have to recognize the inescapable normative work in the choice-of-scope decisions and ensure that all scope decisions are made at a democratic political level. We would need to be constantly vigilant about the political value choices and reflective about who is making those choices. We would need to constantly interrogate how we are constructing the analysis, how it is shaping our politics, and who is benefiting. This would be an explicitly political approach that would constantly reassess how particular political values are being privileged or discounted, whose interests are being promoted or ignored, and how political distributions are being affected. The methods would have to be understood as political —as they are-not scientific, objective, or neutral. 


\section{CONCLUSION}

Systems-analytic methods, such as public policy and CBA, grew out of earlier efforts to systematically and quantitatively evaluate the effectiveness of man-machine systems. But extending the method of OR beyond military weapons systems and into broader social policy contexts has been treacherous and "radical," to borrow Edward Quade's term. It has been radical precisely for the reasons that Quade and his RAND colleagues suggest: the methods take no position on the relative worth of different policies that promote starkly different political values, but the analyses end up significantly reshaping those political values. And that is the nub of the problem: these methods displace democratic debate over the political values we hold as a society.

The systems-analytic methods seduce by suggesting the possibility of avoiding politics, partisanship, or, in James Schlesinger's view, morality and by focusing our attention on narrow objectives that no one could possibly take issue with-like reducing crime or juvenile delinquency. But the methods mask rather than eliminate value judgments and hide the fact that the central, pivotal choice-of-scope decisions at every key step of the analyses are normative political choices through and through. Whenever we ignore or overlook that, we fall once again into the systems fallacy.

It is possible that the current political reaction against the administrative state and Washington technocrats, reflected in the 2016 presidential election, and the ensuing dismantling of regulatory institutions are a reaction against an administrative apparatus that silently imposed values on society under the guise of neutral policy analysis. The political backlash may be, in some part, a rejection of experts imposing political values outside the democratic process. If so, the proper response may call for more express political debate over values_over "morality" — rather than a reinvestment in systems logics, public policy approaches, reconstructed cost-benefit analyses, or other purportedly scientific methods.

\section{REFERENCES}

Ackerman, Frank, and Lisa Heinzerling. 2004. Priceless: On Knowing the Price of Everything and the Value of Nothing. New York: New Press.

Adler, Matthew D., and Eric A. Posner. 2006. New Foundations of Cost-Benefit Analysis. Cambridge MA: Harvard University Press.

- 2008. Happiness Research in Cost-Benefit Analysis. Lournal of Legal 
Studies 37:S253-S292.

- 2009. New Foundations of Cost-Benefit Analysis: A Reply to Professors Sinden, Kysar, and Driesen. Regulation and Governance 3:72-83.

Amadae, S. M. 2003. Rationalizing Capitalist Democracy: The Cold War Origins of Rational Choice Liberalism. Chicago: University of Chicago Press.

Ansell, Christopher K. 2011. Pragmatist Democracv: Evolutionary Learning as Public Philosophv. New York: Oxford University Press.

Balkin, Jack M. 1986. The Crystalline Structure of Legal Thought. Rutgers Law Review 39:1-109.

Beckett, Katherine. 1997. Making Crime Pay: Law and Order in Contemporary American Politics. New York: Oxford University Press.

Blumstein, Alfred. 2007. An OR Missionary's Visits to the Criminal Justice System. Operations Research 55(1):14-23.

Chang, Howard F. 2000a. A Liberal Theory of Social Welfare: Fairness, Utility, and the Pareto Principle. Yale Law Iournal 110:173-235.

- 2000b. The Possibility of a Fair Paretian. Yale Law Journal 110:251-58.

Clarke, Richard A., Michael J. Morell, Geoffrey R. Stone, Cass R. Sunstein, and Peter Swire. 2014. The NSA Report: Liberty and Security in a Changing World. Princeton, NJ: Princeton University Press.

Craswell, Richard. 2003. Kaplow and Shavell on the Substance of Fairness. $\underline{\text { Lour- }}$ nal of Legal Studies 32:245-75.

Dorff, Michael B. 2002. Why Welfare Depends on Fairness: A Reply to Kaplow and Shavell. Southern California Law Review 75:847-99.

Ellingston, John R. 1948. Protecting Our Children from Criminal Careers. Federal Probation 12(3):34-37.

Fagan, Jeffrey A., and Garth Davies. 2003. Policing Guns: Order Maintenance and Crime Control in New York. Pp. 191-221 in Guns, Crime, and Punishment in America, edited by Bernard E. Harcourt. New York: New York University Press.

Fallon, Richard H., Jr. 2003. Should We All Be Welfare Economists? Michigan Law Review 101:979-1025.

Farber, Daniel A. 2009. Rethinking the Role of Cost-Benefit Analysis. University of Chicago Law Review 76:1355-1405.

Ferzan, Kimberly Kessler. 2004. Some Sound and Fury from Kaplow and Shavell. Law and Philosophy 23:73-102.

Geertz, Clifford. 1973. Thick Description: Toward an Interpretive Theory of Culture. Pp. 3-30 in The Interpretation of Cultures. New York: Basic Books.

Harcourt, Bernard E. 2006. From the Asylum to the Prison: Rethinking the Incarceration Revolution. Texas Law Review 84:1751-86.

. 2013. The Influence of Systems Analysis on Criminal Law and Procedure: A Critique of a Style of Judicial Decision-Making. Public Law Research Paper No. 14-562. Columbia Law School, New York. 
2014. The Systems Fallacy: The Perils of Systems Analysis, Past and Present. Working paper. Columbia Law School, New York.

Harcourt, Bernard E., and Jens Ludwig. 2006. Broken Windows? New Evidence from New York City and a Five-City Social Experiment. University of Chicago Law Review 73:271-320.

- 2007. Erratum. University of Chicago Law Review 74:407.

Harrison, Leonard Vance, and Pryor McNeill Grant. 1938. Youth in the Toils. New York: Macmillan.

Hausner, Jack. 1975. Determining the Travel Characteristics of Emergency Service Vehicles. Report No. R-1687-HUD. Santa Monica, CA: RAND Corporation.

Jennings, John B. 1973. Analysis of the Night and Weekend Arraignment Parts in the Bronx and Queens Criminal Courts. Report No. R-1236-NYS. Santa Monica, CA: RAND Corporation.

Kaplow, Louis, and Steven Shavell. 2002. Fairness versus Welfare. Cambridge, MA: Harvard University Press.

- 2003. Fairness versus Welfare: Notes on the Pareto Principle, Preferences, and Distributive Justice. Lournal of Legal Studies 32:331-62.

Kirby, Maurice W. 2003. Operational Research in War and Peace: The British Experience from the 1930s to 1970. London: Imperial College Press.

Kornhauser, Lewis A. 2003. Preferences, Well-Being, and Morality in Social Decisions. Lournal of Legal Studies 32:303-29.

Kysar, Douglas A. 2007. Discounting ... on Stilts. University of Chicago Law Review 74:119-38.

Larson, Richard C. 1971. Response of Emergency Units: The Effects of Barriers, Discrete Streets, and One-Way Streets. Report No. R-675-HUD. Santa Monica, CA: RAND Corporation.

- 1973. A Hypercube Queueing Model for Facility Location and Redistricting in Urban Emergency Services. Report No. R-1238-HUD. Santa Monica, CA: RAND Corporation.

Levitt, Steven D. 2004. Understanding Why Crime Fell in the 1990s: Four Factors That Explain the Decline and Six That Do Not. Lournal of Economic Perspectives 18(1):163-90.

Liebman, James S., Elizabeth Cruikshank, and Christina Ma. 2017. Governance of Steel and Kryptonite Politics in Contemporary Public Education Reform. Florida Law Review 69:365-463.

Liechenstein, Michael I. 1971. Reducing Crime in Apartment Dwellings: A Methodology for Comparing Security Alternatives. Working Paper No. P-4656. New York City-RAND Institute, New York.

Light, Jennifer S. 2003. From Warfare to Welfare: Defense Intellectuals and Urban Problems in Cold War America. Baltimore: Johns Hopkins University Press.

Lindblom, Charles E. 1959. The Science of "Muddling Through.” Public Administration Review 19:79-88. 
1979. Still Muddling, Not Yet Through. Public Administration Review 39:517-26.

MacCormick, Austin H. 1942. Existing Provisions for the Correction of Youthful Offenders. Law and Contemporarv Problems 9:588-99.

New York Times. 1971. Golar Acts to Bolster Security in City Projects. November 18 , p. 52.

Operational Research Society of Great Britain. 1962. News and Notes. Operational Research Ouarterly 13:279-86.

Phillips, Orie L. 1942. The Criminal Youth Problem. American Bar Association Journal 28:581-85.

President's Commission on Law Enforcement and the Administration of Justice. 1967. The Challenge of Crime in a Free Society. Washington, DC: Government Printing Office.

Quade, Edward S. 1966. Systems Analysis Techniques for Planning-ProgrammingBudgeting. Working Paper No. P-3322. RAND Corporation, Santa Monica, CA.

Ranzal, Edward. 1973. Guards to Be Hired to Protect Vest-Pocket Housing Projects. New York Times, April 18, p. 51.

Rosenthal, Jack. 1972. Housing Study: High Rise = High Crime. New York Times, October 26, p. 45.

Rubin, Edward L. 2013. Public Policy and the Methodology of Statutory Design. Paper presented at the Columbia Law School Legal Theory Workshop, New York, September 30.

Sabel, Charles F., and William H. Simon. 2011. Minimalism and Experimentalism in the Administrative State. Georgetown Law Journal 100:53-93.

Schlesinger, James R. 1963. Quantitative Analysis and National Security. World Politics 15:295-315.

Seigel, Max H. 1972. Welfare-Hotel Crime Is a Local Problem. New York Times, November 19, p. 62.

Simon, Herbert A. 1997. Administrative Behavior: A Study of Decision-Making Processes in Administrative Organizations. 4th ed. New York: Free Press.

Sinden, Amy. 2004. Cass Sunstein's Cost-Benefit Analysis: Economics for Liberals. Columbia Journal of Environmental Law 29:191-242.

Sinden, Amy, Douglas A. Kysar, and David M. Driesen. 2009. Cost-Benefit Analysis: New Foundations on Shifting Sand. Regulation and Governance 3:48-71.

Singer, Joseph William. 2002. Something Important in Humanity. Harvard Civil Rights-Civil Liberties Law Review 37:103-30.

Smith, Bruce L. R. 1966. The RAND Corporation: Case Study of a Nonprofit Advisory Corporation. Cambridge, MA: Harvard University Press.

Stewart, Hamish. 2004. Persons and Their Well-Being: A Critical Discussion of Kaplow and Shavell's Fairness versus Welfare. Queen's Law Journal 30:1-34. Stokey, Edith, and Richard Zeckhauser. 1978. A Primer for Policy Analysis. New York: W. W. Norton. 
Sunstein, Cass R. 2001-2. The Arithmetic of Arsenic. Georgetown Law Journal 90:2255-2309.

— 2002. The Cost-Benefit State: The Future of Regulatory Protection. Chicago: American Bar Association.

— 2013. Nonquantifiable. Working paper. Harvard University, Cambridge, MA.

US Army Air Force. 1945. AAF Bombing Accuracy. Washington, DC: Research and Analysis Branch Office of Statistical Control.

US General Accounting Office. 1969. Survey of Progress in Implementing the Planning-Programming-Budgeting System in Executive Agencies: Report to the Congress. Washington, DC: Comptroller General of the United States.

Waldron, Jeremy. 2003. Locating Distribution. Iournal of Legal Studies 32:277302. 